\title{
Integration of High Velocity Elastic Band for Hamstring Training in Pre-Season Routine of Football Players
}

\author{
Donatas Januševičius ${ }^{1}$, Audrius Sniečkus ${ }^{1}$, Mantas Mickevičius ${ }^{1}$, Danguolė Satkunskienė', \\ Pornpimol Muanjai ${ }^{2}$, Sigitas Kamandulis ${ }^{1}$ \\ Lithuanian Sports University ${ }^{l}$, Kaunas, Lithuania \\ Burapha University², Saen Sook, Thailand
}

\begin{abstract}
Background. A need for other methods of hamstring strengthening are thus warranted with the main aim of reducing the risk of injury during the subsequent intense athletic activities. The study aimed to examine changes in hamstring strength in response to high velocity elastic band training when incorporated into regular training routine of football players.

Methods. Research participants were professional top level football players (age 23.1 \pm 5.7 years; weight $77.2 \pm$ $7.7 \mathrm{~kg}$, training experience $14.1 \pm 5.8$ years). In the pre-season, in addition to their routine training, the experimental group performed hamstring curls at maximal intensity while lying prone three times per week for five weeks, while control group continued their routine training. Concentric knee torque at $60 \% \mathrm{~s}$ and $180 \% \mathrm{~s}$ angular velocities, countermovement jump height, $30 \mathrm{~m}$ sprint running performance from standing and flying start, and knee flexionextension movement frequency were measured before and after the 5 weeks of training.

Results. Hamstring curl frequency during lying prone increase by $10.5 \%(p<.05)$ in the experimental group and did not change in the control group. Peak torque for knee flexion and knee extension, jump height and sprint running performance did not change significantly in any group $(p>.05)$.

Conclusion. High velocity elastic band training incorporated into regular pre-season routine is beneficial for football players to increase their knee extension-flexion maximal movement frequency with no evident effects on strength, jump and sprint running performance. Results might be related with concurrent training during preparatory training phase of the pre-season when several physical capacities are being developed simultaneously.
\end{abstract}

Keywords: high speed movements; peak torque; sprint performance; prevention of hamstring injuries; knee flexion strength.

\section{INTRODUCTION}

$\mathrm{D}$ uring the last twenty years, football (soccer) has changed in terms of demands on physical conditioning as well as requirements on muscle supplying energy systems. Recent studies confirm that elite or professional players have become faster while aerobic capacity plateaued or decreased slightly (Haugen et al., 2013; Haugen et al., 2014). In support, Bush et al. (2015) and Barnes et al. (2014) found that players increased sprinting volume by $50 \%$ during the matches of the English Premier League over the period of ten years, whereas total distance covered increased marginally by $\sim 2 \%$ only. Several studies have convinced that acceleration and maximum running velocity distinguishes soccer players of different levels (Haugen et al., 2012; Rebelo et al., 2013; Vescovi, 2012). Sprint running ability studies indicate that professional players from the best European football leagues are faster than players from lower-ranked soccer nations (Rebelo et al., 2013; Dupont et al., 2004). Supporting these results elegant study done by Faude et al. (2012) discovered that straight sprinting without an opponent and without the ball was the most frequent action in 
goal situations in the German Bundesliga during the 2007/08 season.

The ability to produce high horizontal ground reaction force throughout the sprint was the strongest predictor of acceleration and sprint performance of sprint runners of recreational to world-class level (Morin et al., 2015). It has been shown that hamstring muscles play a key role and were singled out as the most important contributor of the highest speed levels (Ishøi et al., 2019; Mann \& Sprague, 1980). From another perspective, hamstring muscle injuries are by far the most frequent injuries reported in soccer, accounting for $37 \%$ of the muscular injuries in the sport (Askling et al., 2013; Van Der Horst et al., 2015). Both low strength and lack of muscle control at high velocities might be related with this high incident rate. These observations strongly advocate for exceptional attention to hamstring muscle strengthening of soccer players for both power development and injury prevention purposes.

Elastic bands may be used to create resistance throughout the range of motion with a velocity and force generation dynamics close to those attained in sport activities as throwing, jumping, or sprinting. Our previous studies have shown that high-velocity elastic-band hamstring training effectively improves muscle power and sprint running performance during non-competitive season (Janusevicius et al., 2017; Kamandulis et al., 2019). However, it remains to be tested how this relatively new training method fits into regular soccer preseason preparation, where high intensity endurance training loads dominate. Elite football players are required to train multiple aspects of physical condition simultaneously. Due to the nature of the competition schedule and short training time available, players often perform sports specific endurance training and heavy load low volume resistance training on the same day (Hoff, 2004). Evidence highlights that when two disparate forms of muscular capacity are trained within the same training cycle, strength and power gains can be impaired, a situation most commonly known as the "interference effect" (Hickson, 1980). Interference effect or concurrent training is defined as simultaneously incorporating resistance and endurance exercise within the same training period. Despite the potential benefits of combining these exercise modes on athletic performance, the majority of studies confirm that gains in muscle hypertrophy, strength and power are compromised when strength- and endurance-based training are undertaken concurrently (Coffey \& Hawley, 2017; Dudley \& Djamil, 1985; Kraemer et al., 1995).
Therefore, the purpose of the present study was to examine how high velocity elastic band training incorporated into regular training routine changes affects hamstring strength as well as fitness of football players during the pre-season preparatory stage. We hypothesized that while such training would increase hamstring muscle power, but, due to the concurrent training, to a smaller extent compared with studies on non-athletes and basketball players (Janusevicius et al., 2017; Kamandulis et al., 2019).

\section{METHODS}

Participants. The highest national football league professional male football players $(n=20$; age, $23.5 \pm 7.2$ years; height, $1.83 \pm 0.05 \mathrm{~m}$; weight, $77.3 \pm 7.7 \mathrm{~kg}$; body mass index (BMI), $23.0 \pm 1.6$ ) were divided equally into the experimental (EG) and control group (CG) by a coach so that the skill level and field positions were matched between groups. The regional ethics committee approved the study. Written informed consent was obtained from each participant.

Training program. In addition to regular training routine, EG participants 3 times per week for 5 weeks (a total of 15 sessions on Mondays, Wednesdays and Fridays, with $\geq 48 \mathrm{~h}$ between each session) performed hamstring curls at a full range of motion and maximal movement rate when lying prone; the exercise was 4-6 sets of 4-s all-out curling with 3-min passive rest between sets. The warm-up consisted of 20 min of specific football drills, dynamic stretching and hamstring curls when lying prone for three sets at intensities of 70,80, and $90 \%$ of maximum. Participants were divided into pairs, where one of them held the elastic band of $1 \mathrm{~m}$ in length fastened with a special strap to the ankles while standing behind, and the other performed the exercise. After each sets the participants of the pairs were changing their roles. When the subject increased movement rate by two cycles per $4 \mathrm{~s}$, resistance was added by increasing the band length by $1 \mathrm{~m}$ each time. All subjects started the program with using elastic band of $1 \mathrm{~m}$ in length. The used elastic bands (TheraBand ${ }^{\mathrm{TM}}$ silver rubber) provide $4.6 \mathrm{~kg}$ of resistance at $100 \%$ elongation. Most subjects were able to reach $300 \%$ elongation during the training program. CG players continued regular training routine. The study was conducted during the pre-season when players trained $1.5-2 \mathrm{~h}$ per session twice per day 5 days per week. High intensity interval training was emphasized as the main 
training mode during this period, and consisted of submaximal 4 min running bouts or playing football in a small field conducted 2 times per week with the heart rate up to 95 percent maximal; also, running accelerations and changes of movement direction for up to $30 \mathrm{~m}$ (8-12 sets with incomplete recovery between sets) were conducted 2 times per week. Strength/power endurance training sessions using additional resistance by weights consisted of squats, jumps, lounges bench press, and core exercises were conducted for 30 min 2 times per week. The remaining workouts were devoted to high volume of technical-tactical training, and a friendly football match once per week.

Pre- and post- training measurements included maximum rate of knee flexion-extension movements and isokinetic concentric knee flexionextension peak muscle torques at $60 \%$ and $180 \% \mathrm{~s}$ knee angular velocities; counter-movement jump $(\mathrm{CMJ}) ; 30 \mathrm{~m}$ running times from stationary and also running start. Before the test participants performed standardized warm-up composed of 10 min pedalling a cycle ergometer followed by $5 \mathrm{~min}$ of dynamic stretching.

Anthropometric measurements. Participants' body height was measured using a height rod, and their body weight using the electronic scales (TBF300 Body Composition Analyzer, Tanita, Philpots Close, UK). Body mass index was calculated $\left(\mathrm{kg} / \mathrm{m}^{2}\right)$.

Knee flexion and extension frequency. We used a Sony $25 \mathrm{~Hz}$ digital camera to record the knee flexion and extension movement frequency. Each participant laid in a prone position on a mattress with the legs straight. Then knee flexion and extension at the full range of motion were performed alternating the legs as quickly as possible for $4 \mathrm{~s}$. The frequency of movements was counted from footage as a number of repetitions per $4 \mathrm{~s}$. Intraclass correlation coefficient of knee flexion/extension frequency was 0.84 .

Dynamometry. An isokinetic dynamometer (System 3; Biodex Medical Systems) was used to measure concentric peak torque of the knee extensor and flexor muscles. With participant seated, his upper body was stabilized with shoulder belts. The distal ends of the thigh and shank were strapped to the seat and the dynamometer arm, respectively. The rotational axis of the dynamometer was aligned with the knee joint axis. The subjects performed three consecutive repetitions with a dominant leg in the concentric mode at angular velocity of $60 \% \mathrm{~s}$ and then at $180 \%$ s with maximal effort. Each set was separated by $2 \mathrm{~min}$ of rest to prevent the fatigue.
The highest peak torques of each set for the flexion and the extension were used for further analysis.

Sprint running timing. Sprint running times over $30 \mathrm{~m}$ were recorded using Brower Timing System (Draper, UT, USA) with photogates placed at $0 \mathrm{~m}, 10 \mathrm{~m}$, and $30 \mathrm{~m}$. Two trials were performed from the starting position, which was $70 \mathrm{~cm}$ from the first gates, and two additional trials were performed from $25-\mathrm{m}$ run up, all completed at maximum efforts. A recovery of about 5 min was allowed between each trial. The better result from each trial was used for analysis. Running time was measured with an accuracy of $1 \mathrm{~ms}$ according to the instrument's manual. High reliability was observed for these tests with the intraclass correlation coefficients above 0.95 .

Countermovement jump. Vertical jump height was measured using the countermovement vertical jump (CMJ) with arm swing on a contact mat (Powertimer Testing System, New Test, Oulu, Finland) starting from an upright standing position with a preliminary downward movement to a knee angle of approximately $90^{\circ}$ with an arm swing. Three trials were performed with $20 \mathrm{~s}$ of passive rest between each trial. The highest jump height was used for analysis in each testing session. If the best result occurred in the third attempt, one additional attempt was performed (Pliauga et al., 2018). The height of the jumps was calculated by applying the following equation: $\mathrm{H}=1.226 \times \mathrm{FT}^{2}(\mathrm{~m})$, where $\mathrm{H}=$ jump height $(\mathrm{m})$ and $\mathrm{FT}=$ flight time (s) $($ Bosco et al., 1982). High test-retest reliability has been previously shown for this test $(\mathrm{ICC}=0.98$ ) (Attia et al., 2017).

Statistical analysis. The data are presented as the arithmetic mean \pm SD. Before the analyses, the Kolmogorov-Smirnov test was used to check the normality of the data distribution. The effects of group (EG vs CG) and time (pre-training vs post-training) on the measured variables were compared using a two-way general linear model repeated-measures ANOVA with appropriate Greenhouse-Geisser correction for sphericity as required. If a significant effect was found, a Tukey post hoc test was performed to locate the differences between means. All of the analyses were performed using IBM SPSS Statistics (IBM Corp., Armonk, NY, USA).

\section{RESULTS}

We tested whether incorporation of low resistance high velocity elastic band training into regular training routine of football players' 
Donatas Januševičius, Audrius Sniečkus, Mantas Mickevičius, Danguolè Satkunskienè, Pornpimol Muanjai, Sigitas Kamandulis INTEGRATION OF HIGH VELOCITY ELASTIC BAND FOR HAMSTRING TRAINING IN PRE-SEASON ROUTINE OF FOOTBALL PLAYERS

Figure 1. Knee flexion-extension frequency during $4 \mathrm{~s}$ period in low load high velocity elastic band (EG) and control group (CG) before and after training (mean $\pm S D)$

Note. $* p<.05$ compared with baseline

Figure 2. Sprint running performance at $10 \mathrm{~m} \mathrm{(A),} 30 \mathrm{~m} \mathrm{(B)}$ and $30 \mathrm{~m}$ flying start (C) after low resistance high velocity elastic band training (EG) and in the control group (CG) $($ mean $\pm S D)$
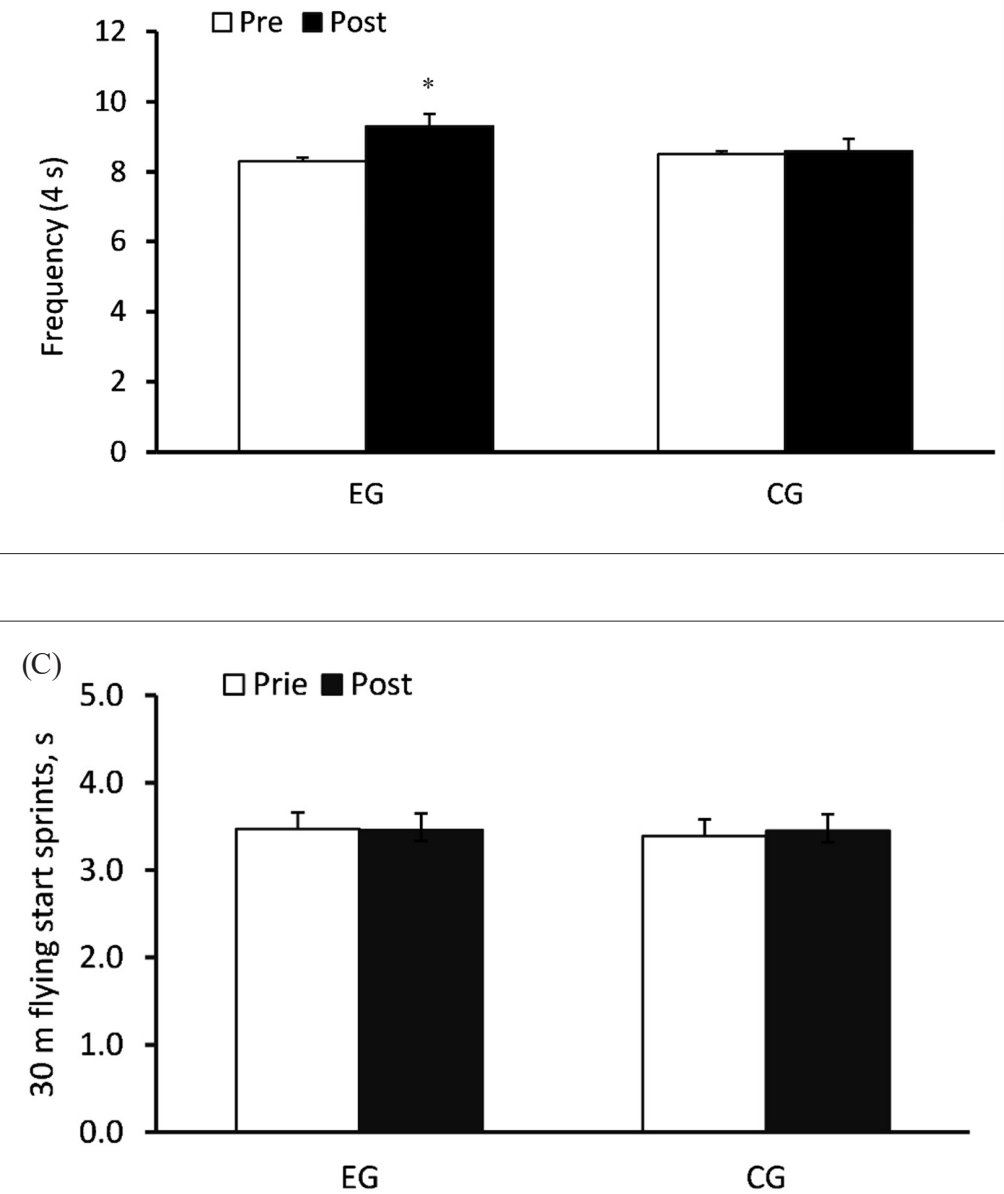

(B)
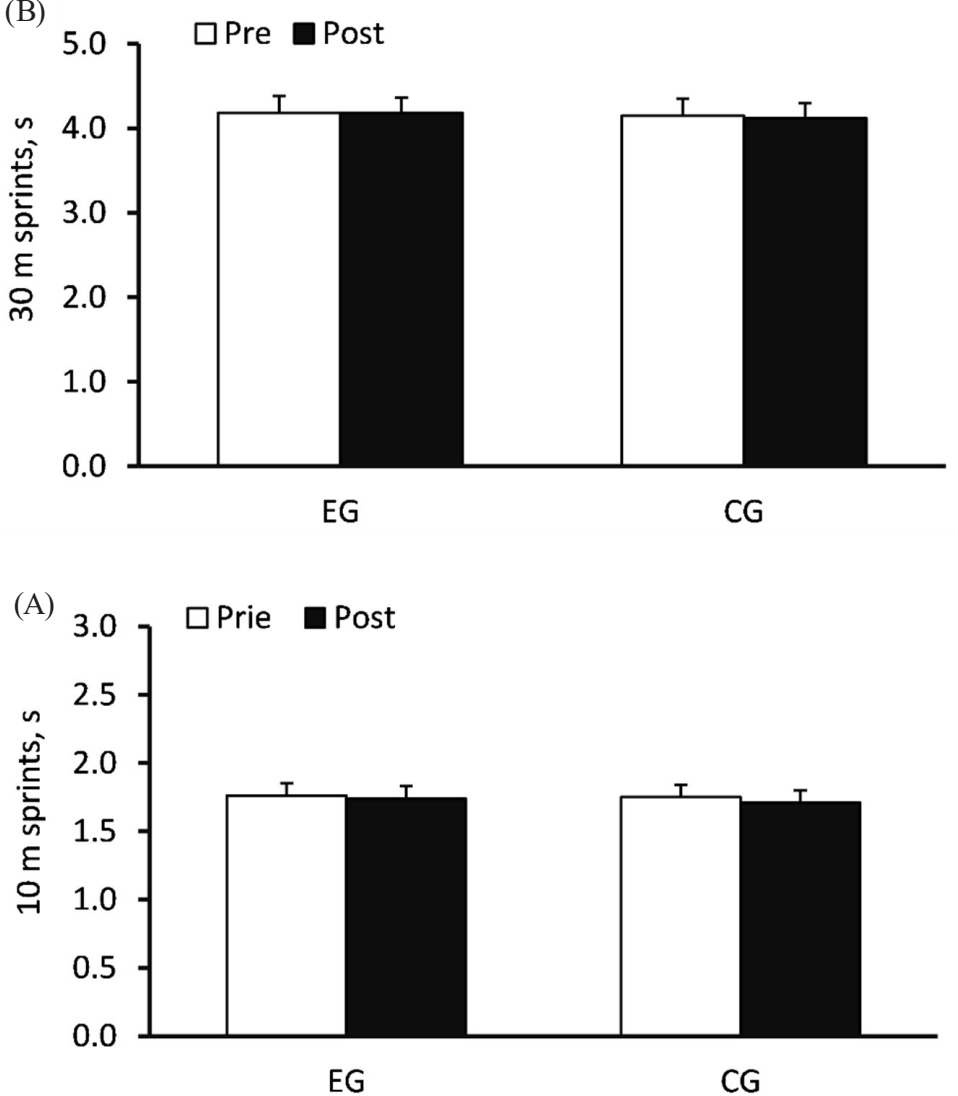
Donatas Januševičius, Audrius Sniečkus, Mantas Mickevičius, Danguolè Satkunskienė, Pornpimol Muanjai, Sigitas Kamandulis INTEGRATION OF HIGH VELOCITY ELASTIC BAND FOR HAMSTRING TRAINING IN PRE-SEASON ROUTINE OF FOOTBALL PLAYERS

Table. Concentric peak torque (Nm) for knee flexion and knee extension

\begin{tabular}{|c|c|c|c|c|c|c|c|c|}
\hline & \multicolumn{4}{|c|}{ Knee flexion } & \multicolumn{4}{|c|}{ Knee extension } \\
\hline & \multicolumn{2}{|c|}{$60 \% / \mathrm{s}$} & \multicolumn{2}{|c|}{$180^{\circ} / \mathrm{s}$} & \multicolumn{2}{|c|}{$60 \% / \mathrm{s}$} & \multicolumn{2}{|c|}{$180^{\circ} / \mathrm{s}$} \\
\hline & Pre & Post & Pre & Post & Pre & Post & Pre & Post \\
\hline EG & 149 (18) & $151(16)$ & 115 (14) & $121(13)$ & 255 (61) & $249(54)$ & 176 (39) & $176(32)$ \\
\hline CG & $153(20)$ & $156(25)$ & $119(15)$ & $124(18)$ & $260(41)$ & $258(33)$ & $182(29)$ & $183(21)$ \\
\hline$T$ test & \multicolumn{2}{|c|}{ None } & \multicolumn{2}{|c|}{ None } & \multicolumn{2}{|c|}{ None } & \multicolumn{2}{|c|}{ None } \\
\hline
\end{tabular}

Notes. Data are mean $\pm S D$. EG, experimental group of football players performed low resistance high velocity elastic band exercise training integrated into regular training routine; $\mathrm{CG}$, control group of football players performed regular training routine.

pre-seasonal-preparatory stage would hamstring performance. The results demonstrated that this additional training increased knee flexionextension movement frequency by $12 \%(p<.05$, Figure 1).

The improvement in knee flexion frequency during $4 \mathrm{~s}$ period in $\mathrm{EG}$ was not accompanied by an improvement in sprint running times over 10 and $30 \mathrm{~m}$ from starting position or $30 \mathrm{~m}$ from a flying start $(\mathrm{p}>0.05)$. . Sprint running performance did not change in CG either $(p>.05)$. Knee flexion and extension concentric peak torques at 60 and $180 \% \mathrm{~s}$ did not change in any group $(p>.05)$. Similarly, $\mathrm{CMJ}$ height pre to post training did not change significantly in any group (CG $49.1 \pm 3.3$ vs. $48.5 \pm$ $5.1 \mathrm{~cm}$; EG $48.9 \pm 4.2$ vs. $48.3 \pm 5.4 \mathrm{~cm}(p>.05))$.

\section{DISCUSSION}

The main finding of the present study is that high velocity elastic band training for hamstrings in addition to pre-seasonal routine of football players was effective in improving knee extensionflexion movement frequency but not vertical jump height, sprint running performance or knee flexion and extension concentric peak torque at either low or high contraction velocity. Small gains in muscle performance (frequency) largely confirmed initial assumption that training effect can be suppressed by application of combined loads during preparatory period, the large part of which was training for the development of endurance capacity.

The neural input of the rapidly contracting skeletal muscle is a critical determinant of neuromuscular performance (Maffiuletti et al., 2016). The magnitude of the neural activation, and hence the force produced by a muscle, depends on the number of motor units activated (recruited) and the rate at which motor neurons discharge action potentials. In the present study, high velocity elastic band training significantly improved knee extension-flexion frequency in professional football players. The mechanism responsible for the observed improvement might be attributed to neural adaptations based on previous findings where positive effects of elastic band training were mainly associated with increase in muscle activation (Kamandulis et al., 2019). This is consistent with the comprehension of the neural adaptation with high intensity training and might include changes in the temporal sequence or frequency of muscle activation (Ross \& Leveritt, 2001).

Other mechanisms contributing to the enhanced movement velocity of the knee extensionflexion may be associated with changes in muscle contractile properties. It was shown that miofiber ATPase activity is influenced by the speed of muscle contraction (Bárány, 1967). In contrast to the ATPase activity of myosin, which varied in association with the speed of muscle contraction, the F-actin-binding ability of myosin from various muscles was rather constant. Thorstensson et al. (1975) have shown that creatine phosphokinase (an enzyme catalysing the breakdown of $\mathrm{PCr}$ ) activity increased by $36 \%$ after short-sprint training (5-second sprints with 25 to 55 second recovery). The velocity of fibre shortening depends not only on myosin composition but also on the rate of intra-fiber $\mathrm{Ca}^{2+}$ cycling. These, in turn, depend on the structure and composition of sarcoplasmic reticulum (SR), $\mathrm{Ca}^{2+}$ sequestering capacity and activity of SR $\mathrm{Ca}^{2+}$ ATPases (SERCAs, or SR $\mathrm{Ca}^{2+}$ "pumps") isoforms of which are expressed differentially in different fibre types (Gundersen, 2011). There are data to suggest that high-intensity sprint training enhances peak $\mathrm{Ca}^{2+}$ release from SR 
due to an enlarged total volume of SR, whereas SR $\mathrm{Ca}^{2+}$ sequestration function is not altered (Ørtenblad et al., 2000).

Importantly, increased frequency of the knee extension-flexion movements in the present study was not accompanied by improvement in performance of vertical jump, sprint running or knee extension-flexion force. This can be explained largely by the specificity of the movements performed with elastic band as it is generally accepted dogma that skeletal muscles adapt specifically to the dominant velocity and force of contraction used during training (Kraemer \& Ratamess, 2004). Movements of knee flexion and extension lying prone are quite different from those performed during jumping, running and isokinetic knee flexions and extensions when seated in the dynamometer chair so the improvement in the frequency of movements in lying position may directly and immediately transfer to other activities. In addition, it might have been that the magnitude of the improvement in knee extension-flexion quickness achieved with specific training was simply not sufficient to improve the performance of the other tests.

Possible reason of small increase in neuromuscular performance might have been due to interfering effect of concomitant strength, power and endurance development (Hickson, 1980; Nelson et al., 1990), high volume of technicaltactical and endurance training (Coutts et al., 2007), inadequate recovery (Coutts \& Reaburn, 2008), and low volume of exposure to power training (Hoffman et al., 1991; Newton et al., 2006). Indeed, more substantial improvement has been found in our previous studies (Janusevicius et al., 2017) where the program was performed by non-athletes as well as basketball players in off-season without concurrent training. In the present study football players were in the pre-season preparatory stage and have been performing a variety of workouts, a large part of which was endurance training, therefore it is quite likely that this interfered with speed and power training. Hickson, with his pioneering work in early 1980s, reported that after a concurrent training (i.e. simultaneous training for strength and endurance) intervention, resistance traininginduced adaptations were blunted compared to the response to solely resistance training. A metaanalysis by Wilson et al. (2012) found that there was an attenuated effect from concurrent training on strength and muscular power adaptation when compared to strength training alone, and that concurrent training does not have an attenuating effect on $\mathrm{VO}_{2} \max$ gains. Power and speed are most negatively affected by concurrent training, and studies show that just a few relatively short endurance sessions per week can blunt their development (Hakkinen et al., 2003; Mikkola et al., 2012).

Our findings on the role of high velocity elastic band training for improving hamstring performance when incorporated into regular training routine of football players complement and extend the elegant study by Aloui et al. (2019) where they used elastic band training during in season for junior male handball players and showed large increase in muscle power. Muscle volume did not increase in their study, implying that increased muscle power was largely due to neuron adaptations, while there was no significant ANOVA interaction on vertical jump performance. Authors concluded that adding two session of elastic band training per week to a standard conditioning regimen yields small gains on parameters that likely have an important influence on handball performance, particularly the ability to sprint and change movement direction. In addition, a study by Andersen et al. (2018) found that short training program with elastic band emphasizing explosive concentric contractions performed 3 times per week incorporated into handball training improved jump height, power output, and velocity of the squat with small weight in young players more substantially than team handball training alone. Finally, the study by Negra et al. (2017) showed the efficacy of 12 week in-season low-to-moderate load high-velocity resistance training added to football practice of prepubertal players on improving squat jump and standing long jump performance and a tendency towards a greater improvement in 1-RM half squat and 10-m sprint running as compared with soccer practice alone. Hence, as all three quoted studies have demonstrated positive outcomes for power production when high-velocity resistance training was performed in season (as opposed with the incorporation it into pre-season in the current study), further research needs to focus on the most adequate integration strategy of such a training into year-round conditioning program of football players. 


\section{CONCLUSIONS}

In conclusion, high velocity elastic band training incorporated into regular pre-season routine is beneficial for football players by increasing knee extension-flexion movement frequency but not strength and sprint performance. Training effect was lower compared to nonathletic population and it might be related with concurrent training content during the football players' pre-season preparatory phase when several physical capacities are developed simultaneously.

Conflict of Interest. The authors declare that they have no conflict of interest.

\section{REFERENCES}

Aloui, G., Hammami, M., Fathloun, M., Hermassi, S., Gaamouri, N., Shephard, J. R., \& Chelly, S. M. (2019). Effects of an 8-week in-season elastic band training program on explosive muscle performance, change of direction, and repeated changes of direction in the lower limbs of junior male handball players. The Journal of Strength and Conditioning Research, 33(7), 1804-1815. doi: 10.1519/JSC.0000000000002786

Andersen, V., Fimland S. M., Cumming T. K., Vraalsen, Ø., \& Saeterbakken, H. A. (2018). Explosive resistance training using elastic bands in young female team handball players. Sports Medicine International Open, 2(6), E171-E178. doi: 10.1055/a-0755-7398

Askling, C. M., Koulouris, G., Saartok, T., Werner S., \& Best, T. M. (2013). Total proximal hamstring ruptures: Clinical and MRI aspects including guidelines for postoperative rehabilitation. Knee Surgery, Sports Traumatology, Arthroscopy, 2(3), 515-533. doi: 10.1007/ s00167-012-2311-0

Attia, A., Dhahbi, W., Chaouachi, A., Padulo, J., Wong, D. P., \& Chamari, K. (2017). Measurement errors when estimating the vertical jump height with flight time using photocell devices: The example of optojump. Biology of Sport, 34(1), 63-70. doi: org/10.5114/ biolsport.2017.63735

Bárány, M. (1967). ATPase activity of myosin correlated with speed of muscle shortening. The Journal of General Physiology, 50(6), 197-218. doi: 10.1085/jgp.50.6.197

Barnes, C., Archer, D. T., Hogg, B., Bush, M., \& Bradley P. S. (2014). The evolution of physical and technical performance parameters in the English Premier League. The International Journal of Sports Medicine, 35(13), 1095-100. doi: 10.1055/s-0034-1375695

Bosco, C., Ito, A., Komi, P. V., Luhtanen, P., Rahkila, P., Rusko, H., \& Viitasalo, T. J. (1982). Neuromuscular function and mechanical efficiency of human leg extensor muscles during jumping exercises. Acta Physiologica Scandinavica, 114(4), 543-550. doi: 10.1111/j.17481716.1982.tb07022.x

Bush, M., Barnes, C., Archer, D. T., Hogg, B., \& Bradley, P. S. (2015). Evolution of match performance parameters for various playing positions in the English Premier League. Human Movement Science, 39, 1-11. doi: 10.1016/j.humov.2014.10.003
Coffey, V. G., \& Hawley, J. A. (2017). Concurrent exercise training: do opposites distract? The Journal of Physiology, 595(9), 2883-2896. doi: 10.1113/JP272270

Coutts, A. J., \& Reaburn, P. (2008). Monitoring changes in rugby league players' perceived stress and recovery during intensified training. Perceptual and Motor Skills, 106(3), 904-916. doi: 10.2466/pms.106.3.904-916

Coutts, A. J., Reaburn, P., Piva, T. J., \& Rowsell, G. J. (2007). Monitoring for overreaching in rugby league players. European Journal of Applied Physiology, 99(3), 313-324. doi: 10.1007/ s00421-006-0345-z

Dudley, G. A., \& Djamil, R. (1985). Incompatibility of endurance- and strength-training modes of exercise. Journal of Applied Physiology, 59(5), 1446-1451. doi: 10.1152/jappl.1985.59.5.1446.

Dupont, G., Akakpo, K., \& Berthoin, S. (2004). The effect of in-season, high-intensity interval training in soccer players. The Journal of Strength and Conditioning Research, 18(3), 584-589. doi: 10.1519/1533-4287(2004)18<584:TEOIHI $>2.0$. CO;2

Faude, O., Koch, T., \& Meyer, T. (2012). Straight sprinting is the most frequent action in goal situations in professional football. Journal of Sports Sciences, 30(7), 625-631. doi: 10.1080/02640414.2012.665940.

Gundersen, K. (2011). Excitation-transcription coupling in skeletal muscle: the molecular pathways of exercise. Biological Reviews of the Cambridge Philosophical Society, 86(3), 564-600. doi: 10.1111/j.1469185X.2010.00161.X

Haugen, T. A., Tønnessen, E., Hem, E., Leirstein, S., \& Seiler, S. (2014). $\mathrm{VO}_{2} \max$ characteristics of elite female soccer players, 1989-2007. International Journal of Sports Physiology and Performance, 9(3), 515-521. doi: 10.1123/ijspp.8.2.148

Haugen, T., Tønnessen, E., \& Seiler, S. (2013). Anaerobic performance testing of professional soccer players 19952010. International Journal of Sports Physiology and Performance, 8(2), 148-156. doi: 10.1123/ijspp.8.2.148 Haugen, T. A., Tønnessen, E., \& Seiler, S. (2012). Speed and countermovement-jump characteristics of elite female soccer players, 1995-2010. International Journal of Sports Physiology and Performance, 7(4), 340-349. doi: 10.1123/ijspp.7.4.340 
Häkkinen, K., Alen, M., Kraemer. W. J., Gorostiaga, E., Izquierdo, M., Rusko, H., Mikkola, J.... Paavolainen, A. (2003). Neuromuscular adaptations during concurrent strength and endurance training versus strength training. European Journal of Applied Physiology, 89(1), 42-52. doi: 10.1007/s00421-0020751-9

Hickson, R. C. (1980). Interference of strength development by simultaneously training for strength and endurance. European Journal of Applied Physiology and Occupational Physiology, 4(2-3), 255-263. doi: 10.1007/BF00421333

Hoff, J., \& Helgerud, J. (2004). Endurance and strength training for soccer players. Sports Medicine, 34 (3), 165180. doi: 10.2165/00007256-200434030-00003

Hoffman, J. R., Fry, A. C., Howard, R., Maresh, C. M., \& Kraemer, W. J. (1991). Strength, speed and endurance changes during the course of a division I basketball season. Journal of Strength and Conditioning Research, 5(3), 144-149.

Ishøi, L., Aagaard, P., Nielsen, M. F., Thornton, K. B., Krommes, K. K., Hölmich, P., \& Thorborg, K. (2019). The influence of hamstring muscle peak torque and rate of torque development for sprinting performance in football players: A cross-sectional study. International Journal of Sports Physiology and Performance, 14(5), 665-673. doi: 10.1123/ijspp.2018-0464.

Ishøi, L., Krommes, K., Husted, R. S., Juhl, C. B., \& Thorborg, K. (2019). Diagnosis, prevention and treatment of common lower extremity muscle injuries in sport - grading the evidence: A statement paper commissioned by the Danish Society of Sports Physical Therapy (DSSF). British Journal of Sports Medicine, 54(9), 528-537. doi: 10.1136/bjsports-101228.

Janusevicius, D., Snieckus, A., Skurvydas, A., Silinskas, V., Trinkunas, E., Cadefau, J. A., \& Kamandulis, S. (2017). Effects of high velocity elastic band versus heavy resistance training on hamstring strength, activation, and sprint running performance. Journal of Sports Science and Medicine, 16(2), 239-246.

Kamandulis, S., Janusevicius, D., Snieckus, A., Satkunskienè, S., Skurvydas, A., \& Degens, H. (2019). High-velocity elastic-band training improves hamstring muscle activation and strength in basketball players. The Journal of Sports Medicine and Physical Fitness, 60(3), 380-387. doi: 10.23736/S0022-4707.19.10244-7

Kraemer, W. J., Patton, J. F., Gordon, S. E., Harman, E. A., Deschenes, M. R., Reynolds, K., Newton, R. U., Triplett, N. T., \& Dziados, J. E. (1995). Compatibility of high-intensity strength and endurance training on hormonal and skeletal muscle adaptations. Journal of Applied Physiology, 78(3), 976-989. doi: 10.1152/ jappl.1995.78.3.976

Kraemer, J. W., \& Ratamess, A. N. (2004). Fundamentals of resistance training: progression and exercise prescription. Medicine \& Science in
Sports \& Exercise, 36(4), 674-688. doi: 10.1249/01. mss.0000121945.36635.61

Maffiuletti, A. P., Aagaard, P., Blazevich, J. A., Folland, J., Tillin, N., \& Duchateau, J. (2016). Rate of force development: Physiological and methodological considerations. European Journal of Applied Physiology, 116(6), 1091-1116. doi: 10.1007/s00421-016-3346-6

Mann, R., \& Sprague, P. (1980). A kinetic analysis of the ground leg during sprint running. Research Quarterly for Exercise and Sport, 51(2), 334-348. doi: 10.1080/02701367.1980.10605202

Mikkola, J., Rusko, H., Izquierdo, M., Gorostiaga, M. E., \& Häkkinen, K. (2012). Neuromuscular and cardiovascular adaptations during concurrent strength and endurance training in untrained men. International Journal of Sports Medicine, 33(9), 702-710. doi: 10.1055/s-0031-1295475

Morin, J. B., Gimenez, P., Edouard, P., Arnal, P., JimenezP., Samozino, P., Brughelli, M., \& Mendiguchia, J. (2015). Sprint acceleration mechanics: The major role of hamstrings in horizontal force production. Frontiers in Physiology, 6, 404. doi: 10.3389/fphys.2015.00404

Negra, Y., Chaabene, H., Hammami, M., Amara, S., Sammoud, S., Mkaouer, B., \& Hachana, Y. (2017). Agility in young athletes: Is it a different ability from speed and power? The Journal of Strength and Conditioning Research, 31(3), 727-735. doi: 10.1519/ JSC.0000000000001543

Nelson, A. G., Arnall, D. A., Loy, S. F., Silvester, L. J., \& Conlee, R. K. (1990). Consequences of combining strength and endurance training regimens. Physical Therapy, 70(5), 287-294. doi: 10.1093/ptj/70.5.287

Newton, R. U., Rogers, R. A., Volek, J. S., Hakkinen, K., \& Kraemer, W. J. (2006). Four weeks of optimal load ballistic resistance training at the end of season attenuates declining jump performance of women volleyball players. Journal of Strength and Conditioning Research, 20(4), 955-961. doi: 10.1519/R-5050502x.1

Ørtenblad, N., Sjogaard, G., \& Madsen, K. (2000). Impaired sarcoplasmic reticulum $\mathrm{Ca}^{2+}$ release rate after fatiguing stimulation in rat skeletal muscle. Journal of Applied Physiology, 89(1), 210-217. doi: 10.1152/ jappl.2000.89.1.210

Pliauga, V., Lukonaitiene, I., Kamandulis, S., Skurvydas, A., Sakalauskas, R., Scanlan, A. T., Stanislovaitiene, J., \& Conte, D. (2018). The effect of block and traditional periodization training models on jump and sprint performance in collegiate basketball players. Biology of Sport, 35(4), 373-382. doi: org/10.5114/biolsport.2018.78058

Rebelo, A., Brito, J., Maia, J., Coelho-e-Silva, M. J., Figueiredo, A. J., Bangsbo, J., Malina, R. M., \& Seabra, A. (2013). Anthropometric characteristics, physical fitness and technical performance of Under19 soccer players by competitive level and field position. 
International Journal of Sports Medicine, 34(4), 312317. doi: 10.1055/s-0032-1323729

Ross, A., \& Leveritt, M. (2001). Long-term metabolic and skeletal muscle adaptations to short-sprint training: implications for sprint training and tapering. Sports Medicine, 31(15), 1063-1082. doi: 10.2165/00007256200131150-00003

Thorstensson, A., Sjödin, B., \& Karlsson, J. (1975). Enzyme activities and muscle strength after "sprint training" in man. Acta Physiologica Scandinavica, 94(3), 313-318. doi: 10.1111/j.1748-1716.1975.tb05891.x

Van der Horst, N., Smits, D. W., Petersen, J., Goedhart, E. A., \& Backx, F. J. (2015). The preventive effect of the nordic hamstring exercise on hamstring injuries in amateur soccer players: A randomized controlled trial. The American Journal of Sports Medicine, 43(6), 1316-1323. doi: 10.1177/0363546515574057

Vescovi, J. D. (2012). Sprint speed characteristics of high-level American female soccer players: Female Athletes in Motion (FAiM) study. Journal of Science and Medicine in Sport, 15(5), 474-478. doi: 10.1016/j. jsams.2012.03.006

Wilson, M. J., Marin, J. P., Rhea, R. M., Wilson, S., Loenneke, P. J., \& Anderson, C. J. (2012). Concurrent training: A meta-analysis examining interference of aerobic and resistance exercises. The Journal of Strength and Conditioning Research, 26(8), 2293-2307. doi: 10.1519/JSC.0b013e31823a3e2d. 